\title{
Relationships of Musculoskeletal Disorder Symptoms and Perceived Workload among Hospital Workers
}

\author{
Taebeum Ryu ${ }^{1}$, Joobong Song ${ }^{2}$, Myung Hwan Yun ${ }^{2}$, Ji Hyoun Lim ${ }^{3}$ \\ ${ }^{1}$ Department of Industrial and Management Engineering, Hanbat National University, Daejeon, 305-719 \\ ${ }^{2}$ Department of Industrial Engineering, Seoul National University, Seoul, 151-744 \\ ${ }^{3}$ Department of Industrial Engineering, Hongik University, Seoul, 121-791
}

\begin{abstract}
Objective: This study aims to survey the prevalence of musculoskeletal disorders(MSD) among Korean hospital workers and to analyze the relationship of MSD symptoms and workload perceived by workers. Background: Despite of high exposure to the MSD risk factors and high MSD symptom prevalence among health care workers, there were not enough studies of MSD prevalence among the hospital workers. Method: This study designed a survey based on Nordic questionnaire to obtain MSD symptoms and the degree of four perceived workloads: work repetition, urgency, physical exertion and satisfaction. In this survey, 1,846 workers in a hospital participated. The prevalence of MSD was analyzed for each body part, and MSD cases, which were predetermined in this study, were identified. The relationship between the MSD cases and each perceived workload was analyzed using chi-square test. Results: The pain in the shoulder was the most prevalent among the workers as 52\%, and the low back(37\%) and leg discomfort(36\%) followed. The MSD cases, in which degree of pain was more than severe, were also the most prevalent in the shoulder(13\%). Female workers had higher rate of MSD cases than the males. Among the four workload variables, the physical exertion was the statistically related to MSD cases for all the body parts. In addition, the others also had significant relation to MSD cases except one or two body parts. Conclusion: This study found that Korean hospital workers had MSD symptoms mainly in the shoulder, low back and legs in order, and the perceived workload surveyed in this study was highly correlated with MSD symptoms. Application: This study provides another evidence that subjective physical exertion perceived by workers is an important factor to explain MSD cases as same as the objective one.
\end{abstract}

Keywords: Musculoskeletal disorder, Hospital workers, Psychosocial factors, Perceived workload

\section{Introduction}

병원 근로자가 수행하는 작업은 높은 반복성, 장시간의 신 체 동작의 요구, 부자연스러운 자세, 강한 힘의 사용 등 대부 분의 근골격계질환 유해요인들을 포함하고 있다. 병원 근로 자들은 전문적으로 분업화된 작업을 단순하고 반복적으로
오랜 시간 동안 수행한다. 또한, 대부분의 병원 근로자들은 비정형 작업들을 불편한 자세로 수행하고, 환자와 무거운 물 건을 옮기는 등의 무리한 육체적 힘을 요구하는 작업들이 수작업으로 이루어지고 있다. 이러한 병원 작업들로 인해 병 원 근로자는 근골격계질환의 작업관련 유해요인에 상당히 노출되어 있다(Park et al., 2005).

국내 및 외국 병원 근로자들의 근골격계질환의 발병률과

Corresponding Author: Taebeum Ryu. Department of Industrial and Management Engineering, Hanbat National University, Daejeon, $305-719$. Mobile: +82-10-6433-2756, E-mail: tbryu75@gmail.com Copyright@2012 by Ergonomics Society of Korea(pISSN:1229-1684 eISSN:2093-8462). All right reserved.

(c) This is an open-access article distributed under the terms of the Creative Commons Attribution Non-Commercial License(http://creativecommons.org/licenses/by-nc/3.0/), which permits unrestricted non-commercial use, distribution, and reproduction in any medium, provided the original work is properly cited. http://www.esk.or.kr 
증상 호소율은 높은 것으로 보고되고 있다. Bernard(1997) 에 따르면 Nursing and personal care facilities의 근골격 계질환 발병률은 $3.2 \%$ 로 다른 산업에 비해 가장 높았다. 이 조사 결과에서 산업평균은 $0.8 \%$ 이었고, 항공운송업 $3 \%$, 음 식가공업 $2.6 \%$, 음료수제조업 $2.5 \%$ 그리고 광산업 $2.3 \%$ 이 었다. Caillard \& Iwatsubo(2000)는 대표적 근골격계질환 발병 부위인 허리의 통증 호소율의 경우 병원관련 종사자 는 약 50\%인 반면, 다른 업종 종사자는 20 50\%라고 보 고하였다. 병원 근로자의 근골격계질환 증상 호소율을 조사 한 연구들도 허리 통증 호소율이 30 86\% 정도라고 하였 다(Murtomaa, 1982; Stubbs et al., 1983; Moens et al., 1994; Niedhammer et al., 1994; Lee and Chiou, 1994; Coggan and Norton, 1995). 허리 통증 외에도 네브라스카 주 치과의사의 팔 근육과 목의 통증 호소율은 29\% (Fish and Morris-Allen, 1998), 치과 기공사의 손과 어깨의 통 증 호소율은 $47 \%$ 와 27\% (Nakladava et al., 1995), 의료 도우미의 무릎 통증 호소율은 39\% (Caillard \& Iwatsubo, 2000), 심장 초음파 검사자의 손목 터널 증후군 증상의 통 증 호소율은 63\%이었다(Vanderpool et al., 1993).

병원 근로자 작업에 근골격계질환 유해요인이 많은 점과 병원 근로자의 높은 근골격계질환 증상 호소율에도 불구하 고, 국내 종합병원 근로자에 대한 근골격계질환 실태조사는 아직 미흡한 형편이다. 국내에서는 자동차, 철강, 조선, 전자 제품 등 제조업 등에 대한 근골격계질환 조사가 주류를 이 루었다(Kim et al.. 2010). 또한, 병원 근로자 중 간호사 등 일부 업종에 대한 연구는 많았으나(Park et al., 2010; Jeong and Koo, 2006; Seo and Kee, 2005), 전체적 병원 근로자 에 대한 근골격계질환 증상의 실태조사는 Park et al.(2008) 에서 이루어졌을 뿐 아직 부족하다.

기존 근골격계질환 실태조사 연구에서는 근골격계질환 증 상 호소와 인지 작업 강도 간의 관계를 파악하였지만, 상세적 인지 작업 강도와의 관계를 파악하는데 미흡하였다. Village (2000)은 병원 세탁소 노동자에 대한 근골격계질환 실태조 사에서 작업 흥미, 작업 변화, 동료 관계, 작업환경에 대한 영향력 등을 나타내는 사회심리학적 변수들과 근골격계질환 증상 호소율 간의 관계를 파악하였다. 그 결과 작업의 다양 성은 통증 적음과 유의한 관계를 갖고, 작업 후 정신적인 피 로는 통증 많음과 유의한 관계를 갖는 등 사회심리학적 변수 들과 근골격계질환 증상 호소율 간의 관계는 유의하였다. 사 회심리학적 변수들의 근골격계질환 증상과의 유의한 관계는 간호사의 일부 인체 부위에서 확인된 바 있다(Lagerström et al., 1995). Bergqvist et al.(1995)는 video display terminal(VDT) 작업에서 유연한 휴식 시간, 동료 접촉, 과 업 유연성과 같은 조직 변수가 근골격계질환 증상에 영향을 주는 요인이라고 보고하였다. Lee et al.(2007)은 자동차 조
립 근로자의 인지 작업 강도와 근골격계질환 증상 간의 관계 를 분석하여 둘 간의 유의한 관계가 있다고 보고하였다. 또 한 Josephson(1997)은 간호사의 근골격계질환 증상 조사 에서 육체적 힘의 사용은 직무 스트레스와 같이 근골격계질 환에 유의한 영향을 준다고 하였다. 그러나 근로자들이 인지 하는 반복성, 촉박성, 물리적 힘 사용의 상세적 작업 강도와 근골격계질환 증상 호소율 간의 관계를 분석한 연구는 아직 미흡하다. 만약 이들의 관계가 유의하다면 종사자들이 인식 하는 개인 및 작업 특성을 조절하는 것도 근골격계질환 관 리하는 효과적인 방법이 될 것이다.

따라서 본 연구는 국내 종합병원 종사자들의 근골격계질 환 증상과 작업 특성을 조사하였고, 병원 종사자들의 부위별 근골격계질환 증상 호소율을 분석하고 직종별 호소율을 비 교하였으며, 종사자의 인지적 작업 강도 및 만족도와 증상 호소율 간의 관계 여부를 파악하고자 하였다. 이를 위해 본 연구는 근골격계질환 증상과 근로자들의 인지적 작업 강도 를 측정하는 설문을 개발하였고, 서울 소재 한 종합병원을 대상으로 실태조사를 통해 근골격계질환에 대한 증상과 인 지적 작업 강도의 관계를 알아보고자 하였다.

\section{Method}

\subsection{Questionnaire}

본 연구의 설문지는 기본 인적 사항, 인지 작업 강도, 근골 격계질환 증상 조사의 세 부분으로 구성되었다. 기본 인적 사항 부분은 성별, 나이, 키, 몸무게, 부서, 업무 및 시간 등 을 기입하도록 구성하였다. 작업 특성 부분은 근로자가 인 식하는 작업의 반복성, 만족도, 촉박성, 육체적 힘의 사용을 5점 Likert scale로 평가하도록 구성되었다. 마지막으로 근 골격계질환 증상 조사 부분은 통증 부위와 통증의 정도를 평가하도록 구성되었다. 본 설문지의 기본 인적 사항, 작업 강도 특성은 Pennsylvania State University MSD Survey form (You, 1999)을 이용하여 작성되었고, 근골격계질환 증 상 조사 부분은 Nordic 설문지를 이용하여 작성되었다.

\subsection{Subjects}

본 종합병원 근로자의 근골격계질환 실태조사 설문에는 서울 소재 한 종합병원의 근로자들이 참여하였다. 이 종합병 원의 전체 근로자는 3,008명으로, 이중 1,846명 (61.4\%)이 조사에 참여하였다 (Table 1). 조사 참여자 중 남성은 $21.5 \%$ (398명), 여성은 $78.5 \%$ (1,454명)으로 참여자의 대부분은 여성이었다. 연령에 따른 참여자의 비율은 20 대가 $43 \%, 30$ 
대가 $36.1 \%, 40$ 대가 $15.8 \%, 50$ 대가 $4.9 \%$ 이었다. 조사 참 여자의 평균 연령은 32 세로 남성의 평균 연령은 36.5 세, 여 성의 평균 연령은 30.9 세 이었다. 조사 참여자의 평균 근무 연수는 7년 9개월로 남성은 8년 7개월, 여성은 7년 6개월 이었다.

Table 1. Composition of responded hospital workers

\begin{tabular}{c|r|r|r|r|r|r}
\hline \multirow{2}{*}{ Age } & \multicolumn{2}{|c|}{ Male } & \multicolumn{2}{c|}{ Female } & \multicolumn{2}{c}{ Total } \\
\cline { 2 - 7 } & Freq. & \multicolumn{1}{c|}{$\%$} & \multicolumn{1}{c|}{ Freq. } & \multicolumn{1}{c}{$\%$} & \multicolumn{1}{c}{ Freq. } & \multicolumn{1}{c}{$\%$} \\
\hline$\leq 29$ & 105 & 26.4 & 692 & 47.6 & 797 & 43.0 \\
\hline $30 \sim 39$ & 138 & 34.7 & 531 & 36.5 & 669 & 36.1 \\
\hline $40 \sim 49$ & 108 & 27.1 & 184 & 12.7 & 292 & 15.8 \\
\hline$\geq 50$ & 43 & 10.8 & 34 & 2.3 & 77 & 4.2 \\
\hline Unclear & 4 & 1.0 & 13 & 0.9 & 17 & 0.9 \\
\hline Total & 398 & 100 & 1,454 & 100 & 1,852 & 100 \\
\hline
\end{tabular}

\subsection{Statistical analysis}

본 연구는 종합병원 근로자의 근골격계질환 실태 설문 결 과에서 인지 작업 강도, 주요 통증 호소 인체 부위, 그리고 작업 강도와 통증 호소율 간의 관계를 분석하였다. 인지 작 업 강도 분석은 반복성, 만족도, 촉박성, 육체적 힘의 사용 정도에 따른 빈도를 분석하였다. 주요 통증 호소 인체 부위 분석은 인체 부위별 통증 정도의 빈도를 분석하여 주요 통증 호소 부위를 파악하였고, 직종에 따른 주요 통증 호소 부위 를 비교하였다. 마지막으로 인지 작업 강도와 통증 호소율 간 관계는 $\chi^{2}$ 검정을 이용하여 분석되었다.

\section{Results}

\subsection{Distribution of perceived workload and work satisfaction}

본 연구의 조사 대상 종합병원 근로자의 인지 작업 반복성 을 분석한 결과, 응답자의 $70 \%$ 정도가 자신의 수행 작업을 반복적으로 인식하고 있었다. 작업 반복성에 대한 동의(그 렇다) 응답이 $48 \%$ (885명)으로 가장 많았고, 중립적 응답 은 23\%(423명), 강한 동의(매우 그렇다) 응답 21\%(384 명), 부정 응답이 $7 \%$ (135명), 강한 부정 응답이 $1 \%$ (19명) 순이었다(Table 2).

인지 작업의 촉박성을 분석한 결과, 응답자의 $57 \%$ 정도 가 자신의 수행 작업이 촉박하다고 인식하고 있었다. 작업
Table 2. Distribution of perceived workload and satisfaction

\begin{tabular}{l|r|r|r|r|r|r|r|r}
\hline & \multicolumn{2}{|c|}{ Repetion } & \multicolumn{2}{c|}{ Urgency } & \multicolumn{2}{c|}{$\begin{array}{c}\text { Physical } \\
\text { exertion }\end{array}$} & \multicolumn{2}{c}{ Satisfaction } \\
\cline { 2 - 9 } & Freq. & $\begin{array}{c}\text { Ratio } \\
(\%)\end{array}$ & Freq. & Ratio & Freq. & Ratio & Freq. & Ratio \\
\hline $\begin{array}{l}\text { Strongly } \\
\text { disagree }\end{array}$ & 19 & 1.0 & 13 & 0.7 & 41 & 2.2 & 23 & 1.2 \\
\hline Disagree & 135 & 7.3 & 184 & 10.0 & 356 & 19.3 & 153 & 8.3 \\
\hline Neutral & 423 & 22.9 & 589 & 31.9 & 601 & 32.6 & 975 & 52.8 \\
\hline Agree & 885 & 48.0 & 811 & 43.9 & 630 & 34.1 & 624 & 33.8 \\
\hline $\begin{array}{l}\text { Strongly } \\
\text { agree }\end{array}$ & 384 & 20.8 & 249 & 13.5 & 218 & 11.8 & 71 & 3.8 \\
\hline
\end{tabular}

*frequency

촉박성에 대한 동의(그렇다) 응답이 $44 \%$ (811명)으로 가장 많았고, 중립적 응답은 $32 \%$ (589명), 강한 동의(매우 그렇 다) 응답 13\%(249명), 부정 응답이 10\% (184명), 강한 부 정 응답이 $1 \%$ (13명) 순이었다.

작업에서 육체적 힘의 사용을 분석한 결과, 응답자의 $46 \%$ 정도가 자신의 수행 작업에 많은 힘이 요구된다고 인식하고 있었다. 육체적 힘의 사용에 대한 동의(그렇다) 응답이 $34 \%$ (630명)으로 가장 많았고, 중립적 응답은 33\%(601명), 부 정 응답이 $19 \%$ (356명), 강한 동의(매우 그렇다) 응답 $12 \%$ (218명), 강한 부정 응답이 $2 \%$ (41명) 순이었다.

작업의 만족도를 분석한 결과, 응답자의 $38 \%$ 정도가 자 신의 수행 작업에 만족하지 않고 있었다. 작업 만족도에 대 한 중립 응답이 53\% (975명)으로 가장 많았고, 부정적 응답 은 34\% (624명), 동의 응답 8\% (153명), 강한 부정 응답이 $4 \%$ (71명), 강한 긍정 응답이 $1 \%$ (23명), 순이었다.

작업의 만족도와 작업 강도와의 상관관계 분석 결과, 작업 만족도와 작업 반복성, 촉박성, 물리적 힘 간의 상관성은 낮 은 것으로 나타났다. 작업 만족도와 작업 반복성 간의 상관 계수는 0.23 , 작업 만족도와 작업 촉박성 간의 상관계수는 0.31 , 작업 만족도와 작업 물리적 힘 간의 상관계수는 0.23 으로 작업 만족도와 인지 작업 강도 간의 상관관계는 유의 하지 않았다 $(\alpha=0.05)$

\subsection{MSD symptoms of hospital workers}

인체 부위별 통증 호소 빈도를 분석한 결과 어깨의 통증 호소가 가장 많았고 허리, 다리의 통증 호소자도 비교적 많 았다(Figure 1). 어깨의 통증 호소자 비율은 $52 \%$ 로 가장 높았고, 허리의 통증 호소자 비율은 $37 \%$, 다리의 통증 호소 자는 $36 \%$ 이었다. 손과 손목의 통증 호소자 비율은 $31 \%$, 목 의 통증 호소자는 $29 \%$ 이었고, 팔과 팔꿈치 통증 호소자 비 
율(17\%)은 가장 작았다.

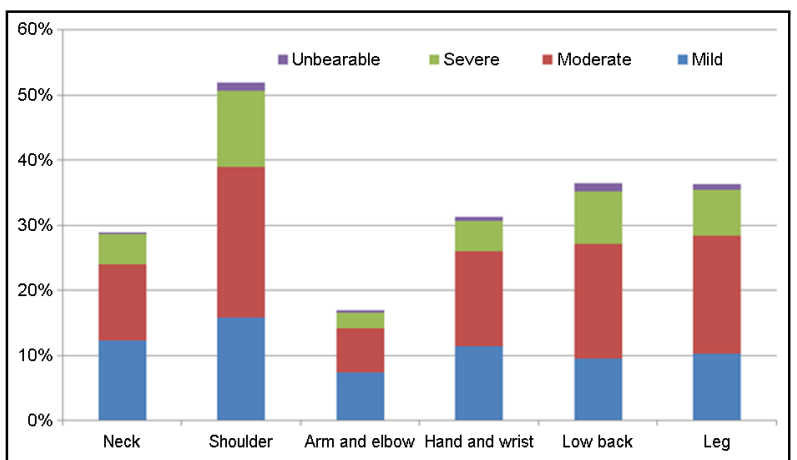

Figure 1. Prevalence of MSD symptom and its severity among hospital workers

통증의 정도가 심각(severe) 수준 이상으로 심한 통증 호소자의 비율도 어깨 부위에서 가장 높았고(13\%), 허리 (9\%)와 다리 $(8 \%)$ 순이었다. 손과 손목, 목, 팔과 팔꿈지 의 심한 통증 호소자의 비율은 $5 \%$ 이하로 적었다.

모든 부위에서 심한 통증 호소자의 빈도는 성별에 따라 유의한 차이를 보였다. $\chi^{2}$ 검정의 분석 결과, 모든 부위에서 심한 통증을 갖는 여성의 관찰 빈도는 기대 빈도보다 많았으 나 남성의 관찰 빈도는 기대 빈도보다 적었다. 특히, 어깨와 다리 부위에서 심한 통증을 호소하는 여성의 수가 남성보다 상당히 많았고, 목 부위에서 그 차이가 다른 부위와 비교하 여 비교적 적었다(Table 3).

종합 병원 근로자의 직종에 따라 통증 호소하는 부위에 차 이가 있었다. 직종에 따라 부위별 심한 통증 호소자 비율 결 과는 그림과 같다. 간호사는 어깨(12\%)와 허리 (12\%) 그리 고 다리 $(11 \%)$ 에 심한 통증을 주로 호소하였고, 운영기능직 (staff)는 목(9\%), 어깨(9\%), 손과 손목(9\%), 허리 (9\%), 다리 $(11 \%)$ 에 비슷한 비율로 통증을 호소하였다. 약무직은 다리에 대한 통증 호소를 하지 않은 반면, 다른 모든 부위에
서 심한 통증을 호소하였다. 나머지 기술직, 수련의, 보건직, 사무직의 심한 통증 호소 비율은 크지 않았다(Figure 2).

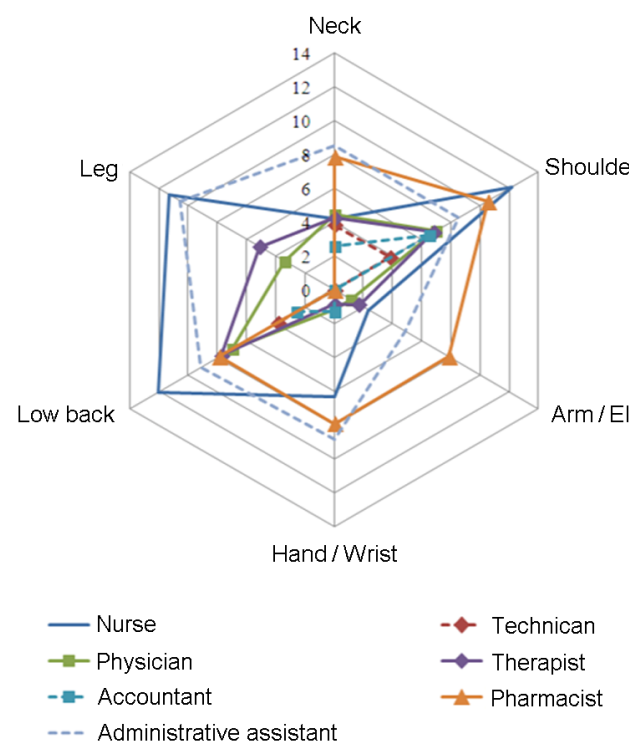

Figure 2. Proportion of MSD cases by worker types

\subsection{Relationship of MSD cases and perceived workload statistical analysis}

병원 근로자의 작업에 대한 반복성, 촉박성, 육체적인 힘 의 사용, 만족도에 따라 신체 부위별 통증 호소자의 빈도가 다른지 $\chi^{2}$ 검정으로 분석하였다. 반복성에 대한 분석 결과, 반복성이 높다고 응답한 그룹에서 모든 부위의 통증 호소율 이 높은 것으로 나타났으며, 팔/팔꿈치를 제외하고 유의한 차이가 있는 것으로 분석되었다(Table 4). 목, 어깨, 손, 허 리, 다리 통증 호소자의 경우 작업 반복성에 대한 중립 의견 이하에서 관찰된 호소자 빈도수는 기대 빈도보다 적었으나, 동조 의견 이상에서 관찰된 호소자 빈도수는 기대 빈도보다

Table 3. Frequency of MSD cases of six body parts between male and female workers

\begin{tabular}{|c|c|c|c|c|c|c|c|c|c|c|c|c|}
\hline & \multicolumn{2}{|c|}{ Neck } & \multicolumn{2}{|c|}{ Shoulder } & \multicolumn{2}{|c|}{ Arm/Elbow } & \multicolumn{2}{|c|}{ Hand/Wrist } & \multicolumn{2}{|c|}{ Low back } & \multicolumn{2}{|c|}{ Leg } \\
\hline & $\mathrm{Ob}$ & Ex. & $\mathrm{Ob}$. & Ex. & $\mathrm{Ob}$. & Ex. & $\mathrm{Ob}$. & Ex. & $\mathrm{Ob}$. & Ex. & $\mathrm{Ob}$. & Ex. \\
\hline Male & 11 & 19.5 & 18 & 51.5 & 1 & 11.1 & 5 & 21.2 & 17 & 37.0 & 6 & 31.9 \\
\hline Female & 79 & 71.1 & 220 & 188.3 & 51 & 40.6 & 94 & 77.3 & 155 & 135.2 & 143 & 116.4 \\
\hline$\chi^{2}$ & \multicolumn{2}{|c|}{4.6} & \multicolumn{2}{|c|}{27.2} & \multicolumn{2}{|c|}{11.9} & \multicolumn{2}{|c|}{15.9} & \multicolumn{2}{|c|}{13.7} & \multicolumn{2}{|c|}{27.0} \\
\hline$p$ & \multicolumn{2}{|c|}{$0.033^{*}$} & \multicolumn{2}{|c|}{$0.000^{* *}$} & \multicolumn{2}{|c|}{$0.0006^{* *}$} & \multicolumn{2}{|c|}{$0.00007^{* *}$} & \multicolumn{2}{|c|}{$0.0002^{* *}$} & \multicolumn{2}{|c|}{$0.000^{* *}$} \\
\hline
\end{tabular}

Ob. Observed frequency of cases, Ex. Expected frequency of cases *significant at $\alpha=0.05,{ }^{* *}$ significant at $\alpha=0.01$ 
Vol. 31, No. 5. 2012. 10.31 Relationships of Musculoskeletal Disorder Symptoms and Perceived Workload among Hospital Workers 691

Table 4. Frequency of cases along with perceived work repetition

\begin{tabular}{|c|c|c|c|c|c|c|c|c|c|c|c|c|}
\hline & \multicolumn{2}{|c|}{ Neck } & \multicolumn{2}{|c|}{ Shoulder } & \multicolumn{2}{|c|}{ Arm/Elbow } & \multicolumn{2}{|c|}{ Hand/Wrist } & \multicolumn{2}{|c|}{ Low back } & \multicolumn{2}{|c|}{ Leg } \\
\hline & $\mathrm{Ob}$ & Ex. & $\mathrm{Ob}$ & Ex. & Ob. & Ex. & $\mathrm{Ob}$. & Ex. & $\mathrm{Ob}$ & Ex. & $\mathrm{Ob}$ & Ex. \\
\hline Strong disagree & 0 & 0.9 & 1 & 2.5 & 0 & 0.5 & 0 & 1.0 & 0 & 1.8 & 0 & 1.5 \\
\hline Disagree & 1 & 6.6 & 4 & 17.6 & 3 & 3.8 & 1 & 7.2 & 7 & 12.6 & 6 & 10.9 \\
\hline Neutral & 13 & 20.6 & 38 & 55.2 & 7 & 11.9 & 12 & 22.7 & 25 & 39.4 & 19 & 34.1 \\
\hline Agree & 40 & 43.2 & 113 & 115.7 & 21 & 25.0 & 45 & 47.5 & 83 & 82.5 & 74 & 71.5 \\
\hline Strong agree & 36 & 18.7 & 85 & 50.1 & 21 & 10.8 & 41 & 20.6 & 57 & 35.7 & 50 & 30.9 \\
\hline$\chi^{2}$ & \multicolumn{2}{|c|}{8.7} & \multicolumn{2}{|c|}{16.8} & \multicolumn{2}{|c|}{3.4} & \multicolumn{2}{|c|}{11.6} & \multicolumn{2}{|c|}{9.5} & \multicolumn{2}{|c|}{10.5} \\
\hline$p$ & \multicolumn{2}{|c|}{$0.034^{*}$} & \multicolumn{2}{|c|}{$0.0008^{* *}$} & \multicolumn{2}{|c|}{0.33} & \multicolumn{2}{|c|}{$0.009^{* *}$} & \multicolumn{2}{|c|}{$0.023^{*}$} & \multicolumn{2}{|c|}{$0.015^{*}$} \\
\hline
\end{tabular}

Ob. Observed frequency of cases, Ex. Expected frequency of cases

*significant at $\alpha=0.05,{ }^{* *}$ significant at $\alpha=0.01$

Table 5. Frequency of cases along with perceived work urgency

\begin{tabular}{|c|c|c|c|c|c|c|c|c|c|c|c|c|}
\hline & \multicolumn{2}{|c|}{ Neck } & \multicolumn{2}{|c|}{ Shoulder } & \multicolumn{2}{|c|}{ Arm/Elbow } & \multicolumn{2}{|c|}{ Hand/Wrist } & \multicolumn{2}{|c|}{ Low back } & \multicolumn{2}{|c|}{ Leg } \\
\hline & $\mathrm{Ob}$. & Ex. & $\mathrm{Ob}$ & Ex. & $\mathrm{Ob}$. & Ex. & $\mathrm{Ob}$. & Ex. & $\mathrm{Ob}$. & Ex. & Ob. & Ex. \\
\hline Strong disagree & 0 & 0.6 & 0 & 1.7 & 0 & 0.4 & 0 & 0.7 & 2 & 1.2 & 1 & 1.0 \\
\hline Disagree & 4 & 9.0 & 14 & 24.0 & 6 & 5.2 & 8 & 9.9 & 9 & 17.1 & 9 & 14.8 \\
\hline Neutral & 23 & 28.7 & 49 & 76.9 & 3 & 16.6 & 17 & 31.6 & 35 & 54.9 & 35 & 47.2 \\
\hline Agree & 40 & 39.5 & 119 & 105.9 & 24 & 22.8 & 45 & 43.5 & 83 & 75.6 & 67 & 65.0 \\
\hline Strong agree & 23 & 12.1 & 59 & 32.5 & 19 & 7.0 & 29 & 13.4 & 43 & 23.2 & 36 & 20.0 \\
\hline$\chi^{2}$ & \multicolumn{2}{|c|}{4.5} & \multicolumn{2}{|c|}{17.6} & \multicolumn{2}{|c|}{11.7} & \multicolumn{2}{|c|}{7.8} & \multicolumn{2}{|c|}{12.3} & \multicolumn{2}{|c|}{5.5} \\
\hline$p$ & \multicolumn{2}{|c|}{0.212} & \multicolumn{2}{|c|}{$0.0005^{* *}$} & \multicolumn{2}{|c|}{$0.009^{* *}$} & \multicolumn{2}{|c|}{$0.049^{*}$} & \multicolumn{2}{|c|}{$0.006^{* *}$} & \multicolumn{2}{|c|}{0.139} \\
\hline
\end{tabular}

Ob. Observed frequency of cases, Ex. Expected frequency of cases *significant at $\alpha=0.05,{ }^{* *}$ significant at $\alpha=0.01$

높음을 볼 수 있다.

촉박성에 대한 분석 결과, 반복성과 같이 작업의 촉박성이 높다고 응답한 그룹에서 모든 부위의 통증 호소율이 높은 것 으로 나타났으며, 목과 다리를 제외한 모든 부위에서 유의한 차이가 있는 것을 분석되었다(Table 5). 어깨, 팔, 손, 허리 통증 호소자의 경우 작업 촉박성에 대한 중립 의견 이하에서 관찰된 호소자 빈도수는 기대 빈도보다 적었으나, 동조 의견 이상에서 관찰된 호소자 빈도수는 기대 빈도보다 높음을 볼 수 있다. 이러한 특성은 목과 다리 부위에서도 발견되지만, 통계적으로 유의하지 않았다.

육체적 힘 사용에 대한 분석 결과, 육제적 힘 사용이 많다 고 응답한 그룹에서 모든 부위의 통증 호소율이 높은 것으로 나타났으며, 모든 부위에서 유의한 차이가 있는 것으로 분석 되었다(Table 6). 모든 부위에서 통증 호소자의 경우 육체 적 힘 사용에 대한 중립 의견 이하에서 관찰된 호소자 빈도 수는 기대 빈도보다 적었으나, 동조 의견 이상에서 관찰된 호소자 빈도수는 기대 빈도보다 높음을 볼 수 있다.
만족도에 대한 분석 결과, 만족하지 않는다고 응답한 그룹 에서 모든 부위의 통증 호소율이 높은 것으로 나타났으며, 팔을 제외한 모든 부위에서 유의한 차이가 있는 것으로 분석 되었다(Table 7). 목, 어깨, 손, 허리, 다리 통증 호소자의 경우 작업 만족에 대한 중립 의견 이상에서 관찰된 호소자 빈도수는 기대 빈도보다 적었으나, 중립 의견 이하에서 관찰 된 호소자 빈도수는 기대 빈도보다 높음을 볼 수 있다.

\section{Discussion and Conclusion}

본 연구의 종합병원 근로자 중 통증 호소자가 많은 부위는 어깨 $(52 \%)$ 인데, 이는 참여 근로자 중 간호사의 비중이 높 기 때문이다. 간호사가 병원 근로자의 대부분을 차지하여 간 호사의 영향이 크므로 종합병원 근로자의 통증 호소 부위 중 어깨가 가장 높은 호소율을 갖는 것으로 사료된다. 간호사 
Table 6. Frequency of cases along with perceived physical exertion

\begin{tabular}{|c|c|c|c|c|c|c|c|c|c|c|c|c|}
\hline & \multicolumn{2}{|c|}{ Neck } & \multicolumn{2}{|c|}{ Shoulder } & \multicolumn{2}{|c|}{ Arm/Elbow } & \multicolumn{2}{|c|}{ Hand/Wrist } & \multicolumn{2}{|c|}{ Low back } & \multicolumn{2}{|c|}{ Leg } \\
\hline & $\mathrm{Ob}$ & Ex. & $\mathrm{Ob}$ & Ex. & Ob. & Ex. & $\mathrm{Ob}$ & Ex. & $\mathrm{Ob}$. & Ex. & Ob. & Ex. \\
\hline Strong disagree & 5 & 2.0 & 6 & 5.3 & 2 & 1.1 & 1 & 2.2 & 2 & 3.8 & 2 & 3.3 \\
\hline Disagree & 11 & 17.2 & 23 & 46.3 & 3 & 9.8 & 9 & 18.7 & 13 & 33.0 & 8 & 28.7 \\
\hline Neutral & 17 & 29.0 & 53 & 78.1 & 7 & 16.6 & 14 & 31.6 & 31 & 55.7 & 28 & 48.5 \\
\hline Agree & 39 & 30.4 & 98 & 81.9 & 28 & 17.4 & 45 & 33.1 & 78 & 58.4 & 71 & 50.9 \\
\hline Strong agree & 17 & 10.5 & 60 & 28.3 & 11 & 6.0 & 28 & 11.5 & 47 & 20.2 & 40 & 17.6 \\
\hline$\chi^{2}$ & \multicolumn{2}{|c|}{14.2} & \multicolumn{2}{|c|}{23.0} & \multicolumn{2}{|c|}{17.4} & \multicolumn{2}{|c|}{19.7} & \multicolumn{2}{|c|}{30.5} & \multicolumn{2}{|c|}{32.1} \\
\hline$p$ & \multicolumn{2}{|c|}{$0.0026^{* *}$} & \multicolumn{2}{|c|}{$0.00004^{* *}$} & \multicolumn{2}{|c|}{$0.006^{* *}$} & \multicolumn{2}{|c|}{$0.002^{* *}$} & \multicolumn{2}{|c|}{$0.000^{* *}$} & \multicolumn{2}{|c|}{$0.000^{* *}$} \\
\hline
\end{tabular}

Ob. Observed frequency of cases, Ex. Expected frequency of cases

*significant at $\alpha=0.05,{ }^{* *}$ significant at $\alpha=0.01$

Table 7. Frequency of cases along with work satisfaction

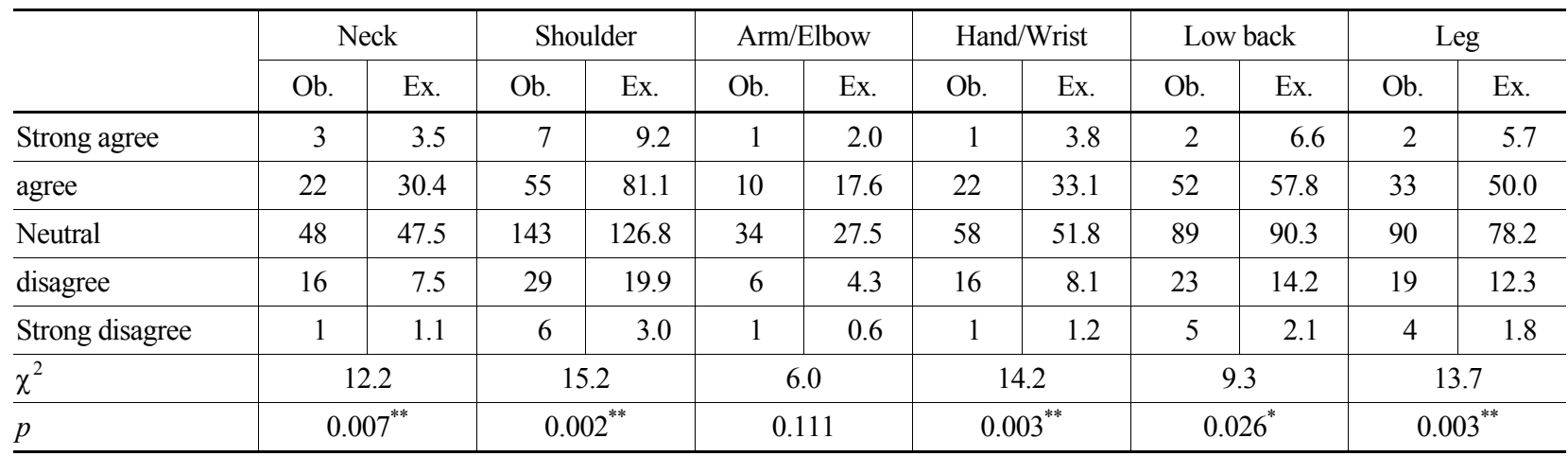

Ob. Observed frequency of cases, Ex. Expected frequency of cases *significant at $\alpha=0.05,{ }^{* *}$ significant at $\alpha=0.01$

직종의 통증 호소율 상위 부위는 어깨, 허리, 다리 순으로, 전체 근로자의 통증 호소율 상위 부위의 순위와 같다. Smith et al. (2003)의 일본 간호사에 대한 근골격계질환 조사에서 어깨의 통증 호소자 비율이 가장 높은 것으로 보고하였고, Bejia et al. (2005) 도 간호사의 근골격계질환 증상 조사에서 통증 호소 순위를 어깨, 허리, 목, 하지 순으로 나타난다고 하였다.

본 조사에서 남성보다 여성의 통증 호소율이 높은 것은 종 합병원의 작업들이 여성 근로자에게 부담이 됨을 의미한다. 본 연구 결과 여성 근로자의 심한 통증 호소자의 빈도수는 기대 빈도수 보다 많은 반면, 남성 근로자의 심한 통증 호소 자의 빈도수는 기대 빈도수 보다 적었다. 이는 병원 여성 근 로자가 남성 근로자에 비해 병원 작업에서 근골격계질환에 높게 노출됨을 나타낸다. 성별은 기존 근골격계질환 증상 조 사 분석에서도 근골격계질환에 영향을 주는 요인으로 분석 되고 있다(Bergqvist et al., 1995; Cha et al., 2007).

본 연구의 종합병원 근로자 중 간호사, 운영기능직, 약무
사 직종의 통증 호소율이 종합병원의 타 직종에 비해 높았 으나 주요 통증 호소 부위는 직종의 특징에 따라 달랐다. 간 호사는 어깨, 허리, 다리에 가장 높은 통증 호소율을 보였고, 운영기능직은 목과 손에, 약무사는 팔과 팔꿈치에 가장 높은 통증 호소율을 보였다. 이는 직종의 작업에 어느 인체 부위 가 주로 사용되는지를 나타낸다. 대표적으로, 이동 거리가 많은 간호사와 운영기능직은 다리 부위에 높은 통증 호소율 을 보였으나, 이동 거리가 적은 약무사는 다리에 통증 호소 를 하지 않았다. 간호사의 어깨 및 허리의 높은 통증 호소율 은 서서 일하거나, 환자의 이동 보조 및 옮김, 무거운 물건 의 이동 등 간호사의 업무 특성과 관련되어 있다(Jeong and $\mathrm{KoO}, 2006)$. 약무사의 팔과 팔꿈치에 나타난 높은 통증 호 소율도 약을 제조하는 이들의 작업 특성과 관련이 있을 것이 다. 다만, 작업 특성과 통증 호소 부위의 객관적 관계 분석을 위해서는 작업환경에 대한 유해요인 조사 및 측정이 필요할 것이다.

본 연구의 작업 강도를 나타내는 변수들 중, 물리적 힘 사 
용이 통증 호소와 가장 높은 관련성을 보였다. 물리적 힘 사 용이 높은 근로자는 그렇지 않는 근로자 보다 모든 부위에서 통증 호소자의 빈도가 기대 빈도보다 많았다. Josephson et al.(1997)은 간호사의 근골격계질환 증상 조사에서 perceived exertion combined with job strain을 근골격계 질환 증상 호소율을 증가시키는 요인으로 결론짓고 있다. Menzel et al.(2004)는 간호사의 물리적 힘 사용이 많은 고 위험의 환자를 다루는 과업의 빈도와 무거운 환자의 취급수 가 근골격계질환 증상에 유의한 영향이 있다고 분석하였다. 본 연구는 물리적 힘 사용의 객관적 변수 외에도 작업자가 인지하는 exertion도 근골격계질환 증상과 유의한 영향이 있음 보여준다.

반복성과 만족도는 대부분의 부위에서 통증 호소와 유의 한 관계를 보였으나 팔과 팔꿈치에서 유의하지 않았다. 또한 작업 촉박성도 목과 다리 두 부위를 제외한 모든 부위에서 통증 호소와 유의한 관계를 보였다. 따라서 본 연구에서 조 사한 인지 작업 강도 특성들은 어느 정도 병원 근로자의 근 골격계질환을 설명하는 요인인 것으로 사료된다. 특히 물리 적 힘 사용은 모든 부위에서 통증 호소와 유의한 관계를 가 져 작업 강도 요인 중 근골격계질환을 가장 잘 설명한다고 볼 수 있다. 특이하게도 작업의 만족도는 통증 호소와 관련 이 매우 높았다.

본 연구는 종합병원 근로자의 근골격계질환 실태 설문 조 사를 수행하였고, 인지 작업 강도와 통증 호소와의 관계를 파악하였다. 종합병원 근로자가 가장 많이 통증을 호소하는 부위는 어깨, 허리, 다리로 이는 간호사의 최대 통증 부위 순 위가 같게 나타났다. 또한 남성보다 여성 근로자가 모든 인 체 부위에서 평균치 보다 높은 통증 호소율을 보였다. 마지 막으로 물리적 힘 사용, 반복성, 만족도 등 인지 작업 특성 들은 거의 모든 인체 부위에서 통증 호소와 유의한 관계를 보였다.

\section{References}

Bejia, I., Younes, M., Jamila, H. B., Khalfallah, T., Ben Salem, K., Touzi, M., Akrout, M. and Bergaoui, N., Prevalence and factors associated to low back pain among hospital staff, Joint Bone Spine, 72(3), 254 $-259,2005$.

Bergqvist, U., Wolgast, E., Nilsson, B. and Voss, M., Musculoskeletal disorders among visual display terminal workers: individual, ergonomics, and work organizational factors, Ergonomics, 38(4), 763 $-776,1995$

Bernard, B. P., A critical review of epidemiological evidence for work- related musculoskeletal disorders of the neck, upper extremity, and low back, National Institute for Occupational Safety and Health, DHHS 97-41(216 p.), Cininnati. OH. 1997.

Caillard, J. F. and Iwatsubo, Y., "Prevalence of Musculoskeletal Disorders among Health Care Workers", Proceedings of the IEA 2000/HFES 2000 Congress (pp. 781-784), San Diego. CA. 2000.

Cha, J., Ryu, T., Choi, H., Lee, J., Kim, M., Chung, M. K. and Jeong, C., Survey of Musculoskeletal Disorders in Korean Dentists, Journal of the Ergonomics Society of Korea, 26(2), 137-147, 2007.

Coggan, C. and Norton, R., Effects on work: nurses and back injury - A qualitative summary, The Journal of Occupational Health and Safety, 11, 489-492, 1995.

Fish, D. R. and Morris-Allen, D. M., Musculoskeletal disorders in dentists, N Y State Dent J, 64, 44-48, 1998.

Jeong, E. H. and Koo, J. W., Analysis of Musculoskeletal Burdened Work among Nurses at a University Hospital, Journal of the Ergonomics Society of Korea, 25(3), 97-103, 2006.

Josephson, M., Lagerström, M., Hagberg, M. and Wigaeus Hjelm, E., Musculoskeletal symptoms and job strain among nursing personnel: a study over a three year period, Occupational and Environmental Medicine, 54, 681-685, 1997.

Kim, K. S., Park, J. K. and Kim, D. S., Status and characteristics of occurrence of work-related musculoskeletal disorders, Journal of the Ergonomics Society of Korea, 29(4), 405-422, 2010.

Lagerström, M., et al. Occupational and individual factors related to musculoskeletal symptoms in five body regions among Swedish nursing personnel, International Archives of Occupational and Environmental Health, 68, 27-35, 1995.

Lee, K. S., et al. "A study on relationships of subjective intensity of work, job stress and self-reported musculoskeletal symptoms", Proceedings of Fall Conference of Ergonomic Society of Korea(pp. 18-23), Busan. Korea. 2007.

Lee, Y. H. and Chiou, W. K., Risk factors for low back pain and patienthandling capacity of nursing personnel, Journal of Safety Research, $25,135-145,1994$

Menzel, N. N., Brooks, S. M., Bernard, T. E. and Nelson, A., The physical workload of nursing personnel: association with musculoskeletal discomfort, International Journal of Nursing Studies, 41, 859-867, 2004.

Moens, G. F., Dohogne, T. H. and Jacques, P. J., Occupation and the prevalence of back pain among employees in health care, Archives of Public Health, 52(5-6), 189-201, 1994.

Murtomaa, H., Work-related complaints of dentists and dental assistants, Int Arch Occup Environ Health, 50, 231-236, 1982.

Nakladalova, M., Fialova, J., Korycanova, H. and Nakladal, Z., State of health in dental technicians with regard to vibration exposure and overload of upper extremities, Central European Journal of Public Health, 3, 129-31, 1995.

Niedhammer, I., Lert, F. and Mame, M. J., Back pain and associated factors in Frcnch nurses, Int Arch Occup Environ Health, 66, 349 $-357,1994$. 
Park, J., Boyer, J., Tessler, J., Perez, G. and Punnett, L., "Exposure Assessment of Musculoskeletal Disorder Risk Factors in Hospital Work: Inter-rater Reliability of PATH Observations", Proceedings of the Human Factors and Ergonomics Society 49th Annual Meeting(pp. 1385-1389), Orlando. FL. 2005.

Park, J. Kim, D. S. and Seo, K. B., "Musculoskeletal disorders and job stress risk factors in general hospital nurses: nursing tasks and musculoskeletal discomfort symptoms", Proceedings of Fall Conference of Ergonomic Society of Korea(pp. 86-89), Pyungchang, Korea. 2010

Park, J., Kim, D. S. and Seo, K. B., Musculoskeletal disorders symptom features and control strategies in hospital workers, Journal of the Ergonomics Society of Korea, 27(3), 81-91, 2008.

Seo, S. R. and Kee, D. H., Survey of Musculoskeletal Disorders Among Nurses in a General Hospital, Journal of the Ergonomics Society of Korea, 24(2), 17-24, 2005.

Smith, D. R., Ohmura, K. Y. and Minai, J., Musculoskeletal disorders among female nurses in a rural Japanese hospital, Nursing and Health Science, 5(3), 85-188, 2003.

Stubbs, D. A., Buckle, P. W., Hudson, M. P., Rivers, P. M. and Worringham, C. J., Back pain in the nursing profession: Epidemiology and pilot methodology, Ergonomics, 26, 755-765, 1983.

Vanderpool, H. E., Friis, E. A., Smith, B. S. and Harms, K. L., Prevalence of carpal tunnel syndrome and other work-related musculoskeletal problems in cardiac sonographers, J Occup Med, 6, 604-610, 1993.

Village, J., "A comparison of case definitions to estimate prevalence of work-related musculoskeletal disorders in hospital laundry workers and the influence of psychosocial variables", Proceedings of the IEA 2000/HFES 2000 Congress(pp. 577-580), San Diego. CA. 2000

You, H., The Development of a Risk Assessment Model for Carpal Tunnel Syndrome. University Park, PA: Pennsylvania State University, Unpublished doctoral dissertation, 1999.

\section{Author listings}

Taebeum Ryu: tbryu75@gmail.com

Highest degree: $\mathrm{PhD}$, POSTECH

Position title: Assistant Professor, Department of Industrial and Management Engineering, Hanbat National University

Areas of interest: MSD, User Interface

Joobong Song: shedtwin@naver.com

Highest degree: BS, Department of Industrial Engineering, Seoul National University

Position title: $\mathrm{PhD}$ candidate, Department of Industrial Engineering, Seoul National University

Areas of interest: MSD, Affective Engineering

Myung Hwan Yun: mhy@snu.com

Highest degree: $\mathrm{PhD}$, Penn State University

Position title: Professor, Department of Industrial Engineering, Seoul National University

Areas of interest: Affective Engineering, User-Centered Product Design

Ji Hyoun Lim: limjh@hongik.ac.kr

Highest degree: $\mathrm{Ph} . \mathrm{D}$., University of Michigan

Position title: Assistant Professor, Department of Industrial Engineering, Hongik University

Areas of interest: Computational Cognitive Modeling, HCI

Date Received : 2012-04-12

Date Revised :2012-09-24

Date Accepted : 2012-09-25 